\title{
The role of hydrogen diffusion, trapping and desorption in dual phase steels
}

\author{
Andreas Drexler ${ }^{1, *}\left(\mathbb{D}\right.$, Besim Helic ${ }^{1}$, Zahra Silvayeh ${ }^{1}$, Klemens Mraczek ${ }^{2}$, Christof Sommitsch ${ }^{1}$, and \\ Josef Domitner ${ }^{1}$ \\ ${ }^{1}$ Graz University of Technology, Institute of Materials Science, Joining and Forming; Research Group of Lightweight and Forming \\ Technologies, Inffeldgasse 11/l, 8010 Graz, Austria \\ ${ }^{2}$ voestalpine Stahl GmbH, voestalpine-Straße 3, 4020 Linz, Austria
}

Received: 24 August 2021

Accepted: 14 December 2021

Published online:

29 January 2022

(C) The Author(s) 2022

\begin{abstract}
Hydrogen embrittlement (HE) of advanced high-strength steels is a crucial problem in the automotive industry, which may cause time-delayed failure of car body components. Practical approaches for evaluating the HE risk are often partially and contradictive in nature, because of hydrogen desorption during testing and inhomogenous hydrogen distributions in, e.g., notched samples. Therefore, the present work aims to provide fully parametrized and validated bulk diffusion models for three dual phase steels to simulate long-range chemical diffusion, trapping and hydrogen desorption from the surface. With one constant set of parameters, the models are able to predict the temperature dependency of measured Choo-Lee plots as well as the concentration dependency of measured effective diffusion coefficients. Finally, the parametrized and validated bulk diffusion models are applied for studying the role of the current density on the permeation time and the role of coatings as effective diffusion barriers.
\end{abstract}

Handling Editor: Megumi Kawasaki.

Address correspondence to E-mail: andreas.drexler@tugraz.at 


\section{GRAPHICAL ABSTRACT}
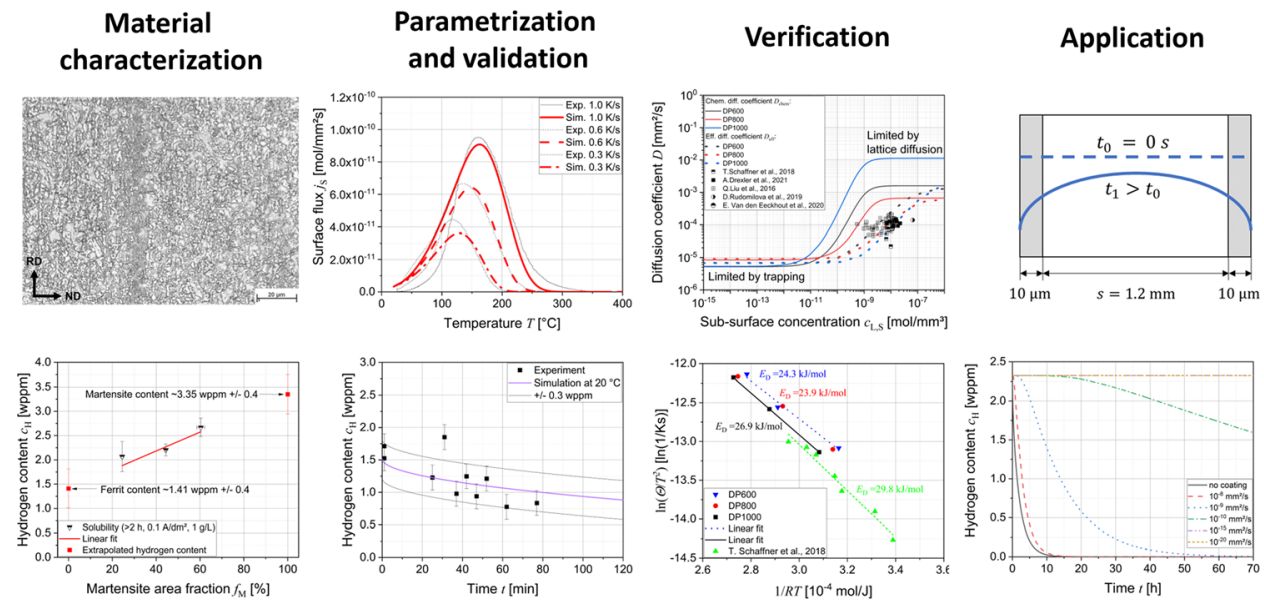

List of symbols

$\alpha, \beta \quad$ Constant pre-factors [wppm]

$c \quad$ Total hydrogen concentration $[\mathrm{mol} / \mathrm{mm} 3]$

$c_{\mathrm{H}} \quad$ Total hydrogen content of a sample [wppm]

$c_{\mathrm{H}, \mathrm{F}} \quad$ Hydrogen content of ferrite [wppm]

$c_{\mathrm{H}, \mathrm{M}} \quad$ Hydrogen content of martensite [wppm]

$c_{\mathrm{L}} \quad$ Lattice hydrogen concentration $[\mathrm{mol} / \mathrm{mm} 3]$

$c_{\mathrm{T}} \quad$ Trapped hydrogen concentration $\left[\mathrm{mol} / \mathrm{mm}^{3}\right]$

$D_{\text {chem }} \quad$ Chemical diffusion coefficient $[\mathrm{mm} 2 / \mathrm{S}]$

$D_{\text {eff }} \quad$ Effective diffusion coefficient $[\mathrm{mm} 2 / \mathrm{S}]$

$D_{\mathrm{L}} \quad$ Tracer diffusion coefficient $[\mathrm{mm} 2 / \mathrm{S}]$

$D_{L, 0} \quad$ Jump frequency $[\mathrm{mm} 2 / \mathrm{S}]$

$\theta \quad$ Heating rate $\left[{ }^{\circ} \mathrm{C} / \mathrm{s}\right]$

$E_{\mathrm{B}} \quad$ Binding energy $[\mathrm{kJ} / \mathrm{mol}]$

$E_{\mathrm{D}} \quad$ Desorption energy $[\mathrm{kJ} / \mathrm{mol}]$

$E_{\mathrm{M}} \quad$ Migration energy $[\mathrm{kJ} / \mathrm{mol}]$

$f_{\mathrm{F}} \quad$ Ferrite area fraction [\%]

$f_{\mathrm{M}} \quad$ Martensite area fraction [\%]

$i \quad$ Current density [A/dm2]

$i^{\infty} \quad$ Stationary current density [A/dm2]

$j_{\mathrm{L}} \quad$ Lattice hydrogen diffusion flux $\left[\mathrm{mol} / \mathrm{mm}^{2} \mathrm{~s}\right]$

$j_{\mathrm{B}} \quad$ Bodyflux [wppm/s]

$j_{\mathrm{S}} \quad$ Surface flux $[\mathrm{mol} / \mathrm{mm} 2 \mathrm{~S}]$

$j_{\mathrm{S}}^{\infty} \quad$ Stationary surface flux $[\mathrm{mol} / \mathrm{mm} 2 \mathrm{~S}]$

$K_{\text {eq }} \quad$ Equilibrium constant [-]

$M_{\mathrm{H}} \quad$ Molar mass of hydrogen $[\mathrm{g} / \mathrm{mol}]$

$N_{\mathrm{L}} \quad$ Density of interstitial lattice sites [mol/ $\left./ \mathrm{mm} 3\right]$
$N_{\mathrm{T}} \quad$ Trap density $[\mathrm{mol} / \mathrm{mm} 3]$

$R \quad$ Universal gas constant $[\mathrm{mJ} / \mathrm{molK}]$

$R_{m} \quad$ Ultimate tensile stress [MPa]

$R_{p 0.2} \quad$ Yield strength [MPa]

$\varrho \quad$ Density of the sample $[\mathrm{g} / \mathrm{mm} 3]$

$s \quad$ Sample thickness [mm]

$T$ Temperature [K]

$T_{\max } \quad$ TDS peak temperature [K]

$t \quad$ Time [s]

$t_{\text {lag }} \quad$ Time-lag [s]

$y_{\mathrm{L}} \quad$ Site fraction of lattice hydrogen [-]

$y_{T} \quad$ Site fraction of trapped hydrogen [-]

\section{Introduction}

Dual phase (DP) steels play an important role in the automotive industry. They are among the first advanced high-strength steels (AHSS) [1] developed for cold-forming applications [2]. The beneficial mechanical properties of DP steels, including high strength paired with high ductility and toughness, can be directly linked to the composite-like microstructure consisting of martensite and ferrite [3-8]. However, with increasing strength DP steels become susceptible to hydrogen embrittlement [9-11], which can cause time-delayed fracture of 
industrial components. Critical hydrogen sources are present during materials processing as well as during service [12, 13]. Hydrogen can be absorbed at the surface, resulting in an inhomogenous hydrogen distribution [14-17] in the steels, which is strongly influenced by plastic deformation [18], residual stresses and edge conditions [19-22]. Hydrogen desorption at room temperature is a crucial problem during testing of hydrogen embrittlement [23], which makes determining the hydrogen embrittlement threshold for a given hydrogen content difficult. According to the ASTM F1624 standard, the so-called threshold stress is "the combined residual and applied stress above which time-delayed fracture will occur (finite life) or below which fracture will never occur (infinite life)". In addition to the hydrogen content, the threshold is sensitive to the applied loading rate [24]. The slower the loading rate, the longer is the total test duration. Typical hydrogen embrittlement tests may run for days to weeks $[13,20,21,25]$. During this time, hydrogen is desorbing from the surface of charged samples, which causes hydrogen diffusion-related difficulties in experimental testing and evaluation of internal hydrogen embrittlement.

Therefore, the present work aims to study hydrogen bulk diffusion in three industrially produced DP steels with ultimate tensile strengths of $659 \mathrm{MPa}$, $834 \mathrm{MPa}$ and $1087 \mathrm{MPa}$. Nowadays in-depth understanding of hydrogen losses during testing, hydrogen uptake or hydrogen permeability, enables optimizing hydrogen embrittlement testing. The required testing time can be minimized and information can be obtained from a test under defined hydrogen charging conditions. For that purpose, physically reasonable bulk diffusion models were developed, parametrized and validated for each investigated DP steel. The models can predict the hydrogen contents after exposure of hydrogen charged samples at room temperature. Furthermore, effective diffusion coefficients were calculated as a function of sub-surface hydrogen coverage at the cathodic side. The comparison of the results with literature data revealed very good understanding of the influence of charging conditions on the stationary anodic currents and the effective diffusion coefficients. Finally, the role of coatings on the hydrogen desorption was simulated and critically discussed with respect to their effective diffusion coefficients.

\section{Experimental methods}

\section{Materials and sample manufacturing}

The investigations were carried out on sheets of three industrially produced DP steels. The as-delivered sheets were zinc-galvanized and had a thickness of $1.2 \mathrm{~mm}$. The steels were designated as DP600, DP800 and DP1000 according to their tensile strengths of $659 \mathrm{MPa}, 834 \mathrm{MPa}$ and $1087 \mathrm{MPa}$, respectively. The chemical composition is given in Table 1 . The tensile properties of the materials were measured according to the DIN EN ISO 6892-1 standard using a Zwick/ Roell Z100 uniaxial testing machine. For that purpose, smooth tensile samples were machined according to DIN 50,125-H. The samples were oriented parallel to the rolling direction (RD) of the sheets. In addition, rectangular-shaped samples of $10 \mathrm{~mm} \times 100 \mathrm{~mm}(\mathrm{RD})$ were machined out of the asdelivered sheets for performing thermal desorption spectroscopy (TDS).

\section{Microstructure characterization}

The microstructures consisting of ferrite and martensite were characterized with a light optical microscope (LOM). For that purpose, samples were ground, polished and etched in a 3 vol. \% Nital solution for $5 \mathrm{~s}$. The samples were immediately cleaned using ethanol and acetone. For each steel, the martensite area fraction was determined in the middle of the sheet thickness using the digital image analysis software ImageJ. The viewing direction is normal to the rolling direction (RD).

\section{Electrochemical charging}

Electrochemical hydrogen charging of the samples was performed by using a Rhode \& Schwarz HMC 8042 power supply at the current density $i$ of $0.1 \mathrm{~A} /$ $\mathrm{dm}^{2}\left(1.0 \mathrm{~mA} / \mathrm{cm}^{2}\right)$. For that purpose, the rectangularshaped samples were ultrasonically cleaned for $2 \mathrm{~min}$ in alkaline fat-dissolving solution, pickled and activated in a $20 \%$ solution of $\mathrm{HCl}$ with $5 \mathrm{~g} / 1$ hexamethylenetetramine $\left(\mathrm{C}_{6} \mathrm{H}_{12} \mathrm{~N}_{4}\right)$ before they were directly immersed into aqueous solution containing $0.5 \mathrm{~mol} / 1 \mathrm{H}_{2} \mathrm{SO}_{4}$ and $1 \mathrm{~g} / 1$ thiourea $\left(\mathrm{CH}_{4} \mathrm{~N}_{2} \mathrm{~S}\right)$. Five samples were charged in parallel using a cylindrically shaped platinum counter electrode with diameter of $40 \mathrm{~mm}$ and height of $50 \mathrm{~mm}$. After $2 \mathrm{~h}$, the 
Table 1 Chemical composition of the investigated cold-rolled DP steels in weight percent (wt\%)

\begin{tabular}{lllllllllll}
\hline Steel & $\mathrm{C}$ & $\mathrm{Si}$ & $\mathrm{Mn}$ & $\mathrm{P}$ & $\mathrm{S}$ & $\mathrm{Al}$ & $\mathrm{Ti}+\mathrm{Nb}$ & $\mathrm{Cr}+\mathrm{Mo}$ & $\mathrm{B}$ & $\mathrm{Cu}$ \\
\hline DP600 & $<0.15$ & $<0.80$ & $<2.50$ & $<0.050$ & $<0.010$ & $0.015-1.5$ & $<0.15$ & $<1.40$ & $<0.005$ & $<0.20$ \\
DP800 & $<0.18$ & $<0.80$ & $<2.50$ & $<0.050$ & $<0.010$ & $0.015-1.0$ & $<0.15$ & $<1.40$ & $<0.005$ & $<0.20$ \\
DP1000 & $<0.20$ & $<1.00$ & $<2.50$ & $<0.050$ & $<0.010$ & $0.015-1.0$ & $<0.15$ & $<1.40$ & $<0.005$ & $<0.20$ \\
\hline
\end{tabular}

homogenously charged samples [26] were gradually removed from the electrolyte, immediately cleaned with water and ethanol and dried with compressed air. The laboratories, in which the measurements were performed, were air conditioned with an average room temperature of $22 \pm 3{ }^{\circ} \mathrm{C}$.

\section{Thermal desorption spectroscopy}

TDS was performed by using a Bruker G8 Galileo analyser equipped with an infrared furnace and a thermal conductivity detector (TCD). Three different heating rates were applied, namely $0.3 \mathrm{~K} / \mathrm{s}, 0.6 \mathrm{~K} / \mathrm{s}$ and $1.0 \mathrm{~K} / \mathrm{s}$. All samples were heated up to $400{ }^{\circ} \mathrm{C}$ to desorb diffusible hydrogen from the sample surface. The actual temperature of each sample was measured using an additional thermocouple placed next to the sample in the infrared furnace [27]. After each measurement, the furnace was cooled to room temperature. The hydrogen content was determined by integrating the measured TDS spectrum. The desorption energy $E_{\mathrm{D}}$ was calculated from the measured TDS spectrum according to Kissinger's theory [28-30]:

$E_{\mathrm{D}}=-R \frac{\mathrm{d}\left(\ln \left(\theta / T_{\max }^{2}\right)\right.}{\mathrm{d}\left(1 / T_{\max }\right)}$

where $\theta$ is the heating rate, $T_{\max }$ is the TDS peak temperature, and $R$ is the universal gas constant. As shown in a previous work, Eq. (1) is only applicable in case of single TDS speaks or well separated TDS peaks [31]. The TDS peak temperatures were determined in a rather straightforward manner without fitting of Gaussian curves.

\section{Numerical methods}

\section{Bulk diffusion modelling}

Chemical bulk diffusion of hydrogen in DP steels is described by Fick's second law of diffusion $[30,32,33]$ as

$\frac{\mathrm{d} c}{\mathrm{~d} t}=\nabla\left(D_{\text {chem }} \nabla c\right)$

where $c$ is the total molar hydrogen concentration and $D_{\text {chem }}$ is the concentration-dependent chemical diffusion coefficient [34]. The total molar hydrogen concentration $c$ can be written as the sum of the lattice hydrogen concentration $c_{\mathrm{L}}$ and the trapped hydrogen concentration $c_{\mathrm{T}}$ as

$c=c_{\mathrm{L}}+c_{\mathrm{T}}$

The corresponding total hydrogen content $c_{\mathrm{H}}$ is calculated from the molar total hydrogen concentration $c$ as follows:

$c_{H}=\frac{c \cdot 10^{6} \cdot M_{\mathrm{H}}}{\varrho}$

where $M_{\mathrm{H}}$ is the molar mass of hydrogen and $\varrho$ is the density of the sample. Lattice hydrogen occupies two different types of interstitial lattice sites in bodycentred cubic (bcc) iron, namely tetrahedral and octahedral sites [35]. According to Kholtobina et al. [36], the solution energies $E_{S}$ of tetrahedral and of octahedral sites are $0.23 \mathrm{eV}$ and $0.37 \mathrm{eV}$, respectively. Due to the difference of $0.14 \mathrm{eV}$, tetrahedral sites are favored to be occupied by hydrogen at room temperature, but it is likely that also octahedral sites get thermally activated during temperature ramping [37]. Trapped hydrogen can be regarded as reversibly trapped, whenever hydrogen absorption and/or desorption occur without significant microstructural changes at the sample surface. Typical reversible hydrogen trapping sites are directly accessible from the lattice sites, such as vacancies [25, 36, 38, 39], dislocations [25, 38, 40], grain boundaries [36, 38, 41] 
or carbide interfaces [42-46]. According to McNabb and Foster [47], lattice hydrogen diffuses freely through the crystal structure, but trapped hydrogen exchanges only locally with lattice hydrogen. The lattice hydrogen diffusion flux $j_{\mathrm{L}}$ [48] is given as

$j_{\mathrm{L}}=-D_{\mathrm{L}} \nabla c_{\mathrm{L}}=-D_{\mathrm{L}, 0} \exp \left(-E_{\mathrm{M}} / R T\right) \nabla c_{\mathrm{L}}$

where $D_{\mathrm{L}}$ is the lattice diffusion coefficient, $D_{\mathrm{L}, 0}$ is the jump frequency, $E_{\mathrm{M}}$ is the migration energy, and $T$ is the absolute temperature. $D_{\mathrm{L}, 0}$ was $0.133 \mathrm{~mm}^{2} / \mathrm{s}$ [37, 49-52]. In bcc iron, the local hydrogen exchange between lattice sites and trapping sites is magnitudes faster than the long-range chemical diffusion $[19$, 32, 53]. That fulfils the local equilibrium assumption according to Oriani's theory [32], which is

$\frac{y_{\mathrm{L}}\left(1-y_{\mathrm{T}}\right)}{y_{\mathrm{T}}\left(1-y_{\mathrm{L}}\right)}=K_{\mathrm{eq}}=\exp \left(-\frac{E_{\mathrm{B}}}{R T}\right)$

$K_{\text {eq }}$ is the equilibrium constant, $y_{\mathrm{L}}=c_{\mathrm{L}} / N_{\mathrm{L}}$ is the site fraction of freely diffusing lattice hydrogen, $N_{\mathrm{L}}$ is the density of interstitial lattice sites, $y_{\mathrm{T}}=c_{\mathrm{T}} / N_{\mathrm{T}}$ is the site fraction of trapped hydrogen, and $N_{\mathrm{T}}$ is the density of trapping sites. The density of lattice sites $N_{\mathrm{L}}$ was $2.04 \bullet 10^{-4} \mathrm{~mol} / \mathrm{mm}^{3}$ [48]. The binding energy $E_{\mathrm{B}}$ depends on the dominant type of hydrogen trapping sites [36, 44, 54,55] in the microstructure. According to Oriani's theory, the concentration-dependent chemical diffusion coefficient in Eq. (2) yields

$D_{\text {chem }}=\frac{D_{\mathrm{L}}}{2}\left(1+\frac{\frac{c\left(1-K_{\mathrm{eq}}\right)}{N_{\mathrm{L}}}-\frac{N_{\mathrm{T}}}{N_{\mathrm{L}}}+K_{\mathrm{eq}}}{\sqrt{\left(\frac{c\left(1-K_{\mathrm{eq}}\right)}{N_{\mathrm{L}}}-K_{\mathrm{eq}}-\frac{N_{\mathrm{T}}}{N_{\mathrm{L}}}\right)^{2}+\frac{4 c K_{\mathrm{eq}}\left(1-K_{\mathrm{eq}}\right)}{N_{\mathrm{L}}}}}\right)$

Fitting the predictions of the bulk diffusion model to the measured TDS spectrum enables determining the binding energy, the trap density and the migration energy [20, 25, 38, 42, 43]. For that purpose, the bulk diffusion as given in Eq. (2) was numerically calculated using an implicit solution algorithm with equidistant nodes. The distance between each node was $1 \mu \mathrm{m}$. The timestep was $1 \mathrm{~s}$, which was sufficient for time convergence. Dirichlet boundary conditions were applied with constant sub-surface lattice hydrogen concentration $c_{\mathrm{L}, \mathrm{S}}$. The initial lattice hydrogen concentration, and thus the trapped hydrogen concentration, were assumed as homogeneously distributed inside the sample after charging. Transportation time of 2 min (120 s) between charging and TDS was considered in the model. During this time, hydrogen was allowed to desorb from the surface at room temperature, causing a cosinusoidal profile of hydrogen concentration before temperature ramping. The routine for parameter optimization was developed in former works by the authors, and it uses the least square minimization method available in Python [38, 42, 43].

\section{Results and discussion}

\section{Material characterization}

Figure 1 shows representative LOM images of the microstructures of the investigated DP steels. The images were taken from central positions of the samples, and the viewing direction is normal to the rolling direction (RD), as indicated in Fig. 1. The dark areas represent martensite, while ferrite appears as white in the micrographs. DP600 and DP1000 have a more equiaxed microstructure with small martensite islands surrounding the ferrite grains. DP800 has a more banded microstructure [56]. DP600, DP800 and DP1000 contain martensite area fractions $f_{M}$ of $25 \%$, $44 \%$ and $59 \%$, respectively. It is obvious that the ferrite grain sizes are significantly different and they decrease with increasing martensite area fraction.

Figure $2 \mathrm{a}$ shows the measured engineering stressstrain curves of the investigated DP steels. The corresponding tensile properties are summarized in Table 2. DP600 has lowest yield strength and ultimate tensile strength of $366 \mathrm{MPa}$ and $659 \mathrm{MPa}$, respectively, but largest fracture strain of $25 \%$. DP1000 has the highest yield strength and ultimate tensile strength of $732 \mathrm{MPa}$ and $1087 \mathrm{MPa}$, respectively, but the smallest fracture strain of $13 \%$. DP800 has intermediate tensile properties with yield strength of $518 \mathrm{MPa}$, ultimate tensile strength of $834 \mathrm{MPa}$ and fracture strain of $19 \%$. As shown in Fig. 2b, the ultimate tensile strength increases almost linearly with increasing martensite area fraction. The linear correlation agrees with literature data between 20 and $70 \%$ of martensite area fraction. Beside the martensite area fraction, the carbon content of martensite affects the ultimate tensile strength of DP steels [57]. The latter was not considered in the present work. That might 
Figure 1 LOM images of the microstructures of the investigated DP steels: a DP600, b DP800 and c DP1000.. (a)

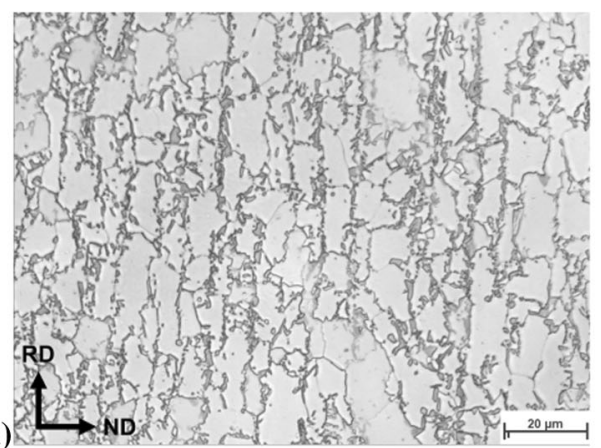

(b)

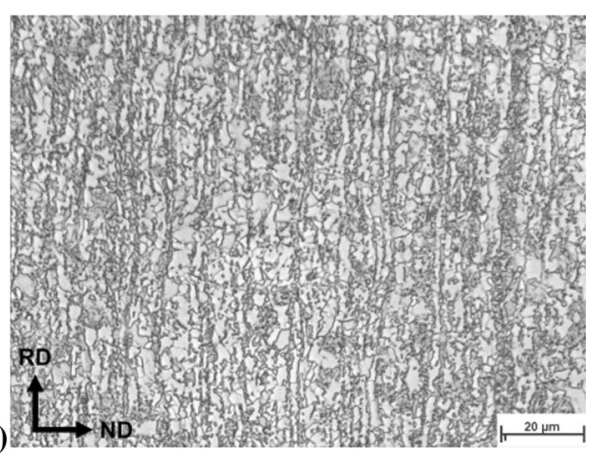

(c)

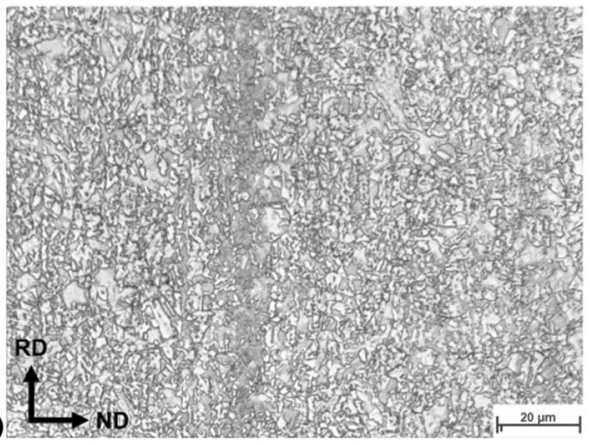

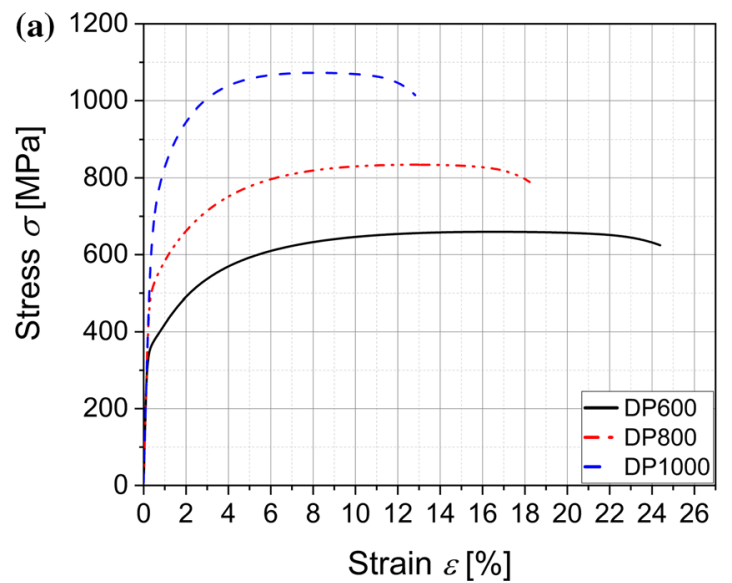

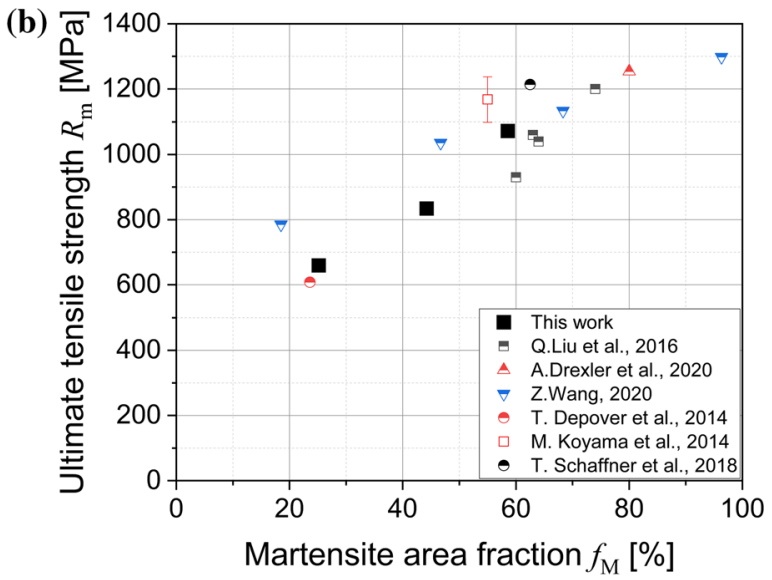

Figure 2 a Measured engineering stress-strain curves and $\mathbf{b}$ correlation of the ultimate tensile strength with the martensite area fraction.

Table 2 Mechanical properties of the investigated DP steels

\begin{tabular}{llll}
\hline Steel & Yield strength $\boldsymbol{R}_{\boldsymbol{p} 0.2}[\mathrm{MPa}]$ & Ultimate tensile strength $\boldsymbol{R}_{\boldsymbol{m}}[\mathrm{MPa}]$ & Fracture strain $\boldsymbol{A}_{50}[-]$ \\
\hline DP600 & 366 & 659 & $25 \%$ \\
DP800 & 518 & 834 & $19 \%$ \\
DP1000 & 732 & 1087 & $13 \%$ \\
\hline
\end{tabular}

be the reason for the difference of almost $200 \mathrm{MPa}$ to the data provided by Wang [58]. With increasing ultimate tensile strength also work hardening increased, which can significantly affect the hydrogen embrittlement susceptibility of the investigated DP steels [19].

\section{Characterization of hydrogen content and desorption energy}

Figure 3 shows the measured TDS spectra of the investigated DP steels. The maxima of the spectra are located between 107 and $175{ }^{\circ} \mathrm{C}$. With increasing 

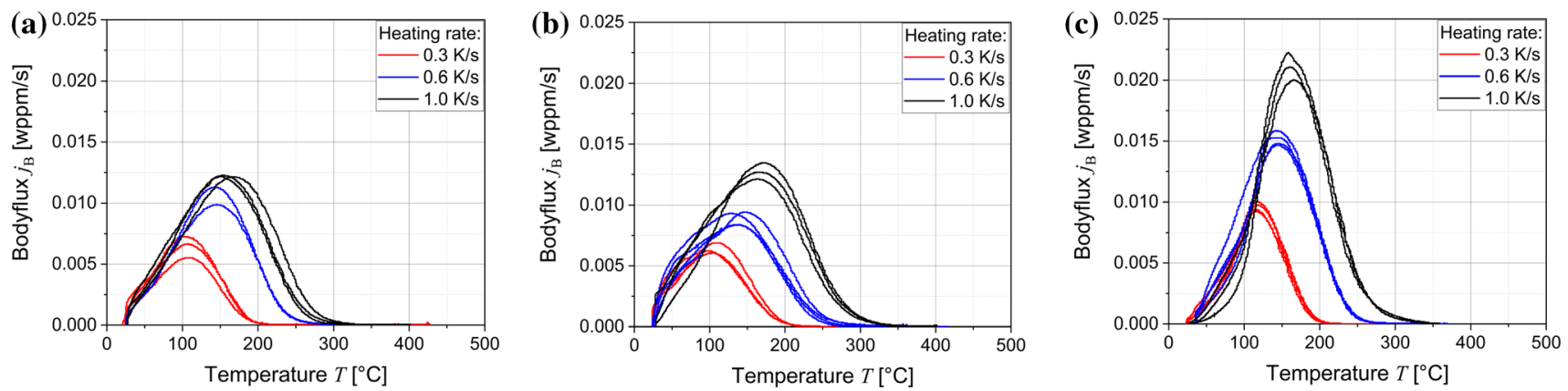

Figure 3 Measured TDS spectra of the investigated DP steels: a DP600, b DP800 and c DP1000.

heating rate, the maxima shift to higher temperatures and the areas under the curves increase. Each TDS measurement was repeated several times with good reproducibility, as shown in Fig. 3. The TDS peak temperatures were determined within $\pm 5^{\circ} \mathrm{C}$. The corresponding hydrogen contents were $2.07 \pm 0.31$ wppm, $2.20 \pm 0.12 \mathrm{wppm}$ and $2.67 \pm 0.19 \mathrm{wppm}$ for DP600, DP800 and DP1000, respectively. The relationship between hydrogen content and martensite area fraction is shown in Fig. 4a. For the given charging conditions, the measured hydrogen contents increase linearly with increasing martensite area fraction, which could be due to hydrogen trapping at dislocations $[38,41]$ in martensite, the lath martensite boundaries [20,42,43] or at ferrite/martensite interfaces $[59,60]$. This is in accordance with the experimental observations of Rudomilova et al. [61], who estimated trap densities and effective diffusion coefficients of AHSS steel sheets as a function of the interface area between ferrite and martensite.

By considering the well-known rule of mixture as
$c_{\mathrm{H}} \cong \alpha \cdot f_{\mathrm{F}}+\beta \cdot f_{\mathrm{M}}=\alpha \cdot\left(1-f_{\mathrm{M}}\right)+\beta \cdot f_{\mathrm{M}}$

and by using the measured total hydrogen contents $c_{\mathrm{H}}$ as function of martensite area fraction $f_{\mathrm{M}}$ (as shown in Fig. 4a), one can directly estimate the hydrogen content of ferrite phases as

$c_{\mathrm{H}, \mathrm{F}}=\alpha \cdot f_{\mathrm{F}}=\alpha \cdot\left(1-f_{\mathrm{M}}\right)=1.41 \cdot\left(1-f_{\mathrm{M}}\right)$

and of martensite phases as

$c_{\mathrm{H}, \mathrm{M}}=\beta \cdot f_{\mathrm{M}}=3.35 \cdot f_{\mathrm{M}}$

$\alpha$ and $\beta$ are 1.41 and 3.35 wppm, representing the hydrogen contents of ferrite and martensite for the given charging conditions. $f_{\mathrm{F}}$ and $f_{\mathrm{M}}$ are the ferrite and martensite area fractions, respectively, and were measured by using metallographic characterization. Thus, martensite with higher defect densities stores almost twice as much hydrogen than ferrite.

For identifying dominating hydrogen trapping sites acting on the diffusion process and solubility, the desorption energies $E_{\mathrm{D}}$ according to Kissinger's
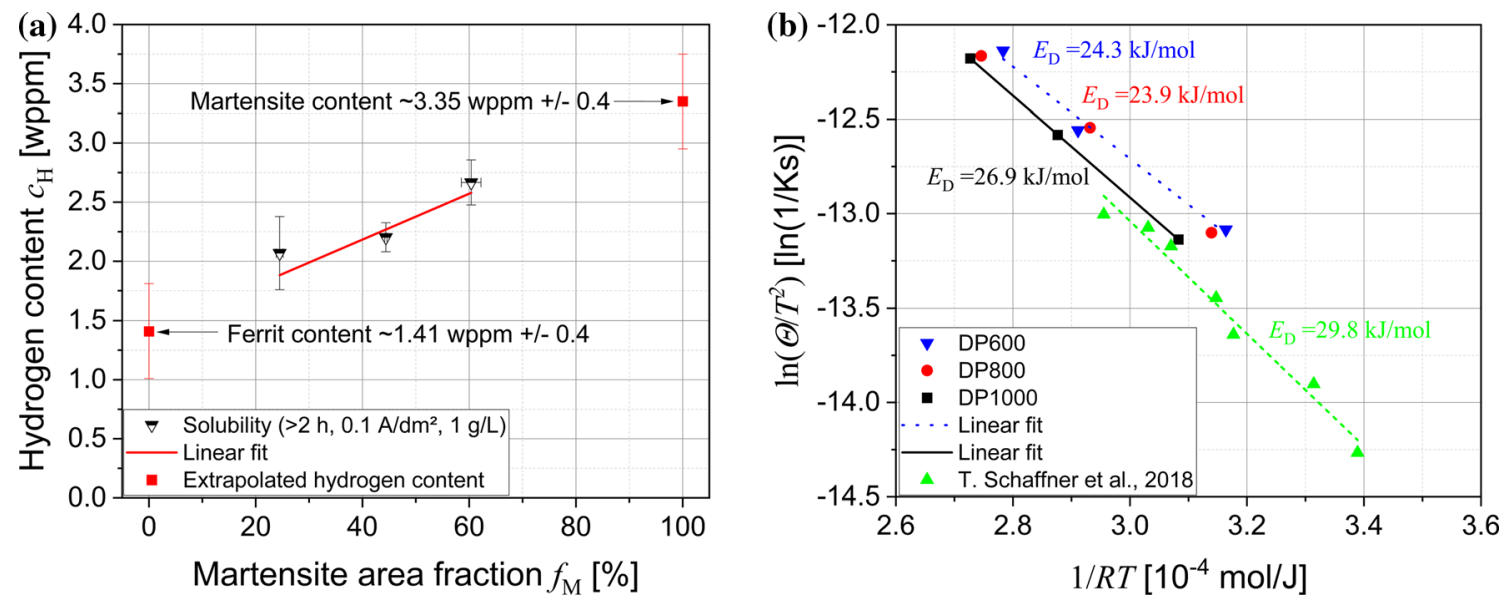

Figure 4 a Measured hydrogen content of investigated DP steels as a function of area fraction of martensite $\mathbf{b}$ Choo-Lee plot of investigated DP steels to evaluate desorption energies according to Kissinger's theory.. 
theory were evaluated. Therefore, the TDS peak temperatures were used to generate Choo-Lee plots for each DP steel, as shown in Fig. $4 \mathrm{~b}$. Linear fits according to Eq. (1) revealed $R^{2}$-values of almost 1 [31] and corresponding desorption energies of $24.3 \mathrm{~kJ} / \mathrm{mol}, 23.9 \mathrm{~kJ} / \mathrm{mol}$ and $26.9 \mathrm{~kJ} / \mathrm{mol}$ for DP600, DP800 and DP1000, respectively. This is in very good agreement with desorption energies published in literature [20, 62]. Table 3 summarizes desorption energies $E_{\mathrm{D}}$ and corresponding $R^{2}$-values. For example, Schaffner et al. [62] performed TDS measurements on a DP steel with ultimate tensile strength of $1200 \mathrm{MPa}$ and lower hydrogen content of $0.68 \mathrm{wppm}$. The corresponding Choo-Lee plot was added to Fig. $4 \mathrm{~b}$. The linear extrapolation to lower heating rates in Fig. $4 \mathrm{~b}$ is reasonable with respect to the results of the present work.

The desorption energy $E_{\mathrm{D}}$ according to Kissinger's theory [31] can be used to calculate the rate-determining step during thermal desorption of hydrogen. In the case of bulk diffusion, the rate-determining step is the thermal activation of long-range chemical diffusion. The Kirchheim criterium [30, 31, 63] applies, which links the desorption energy $E_{\mathrm{D}}$ and the binding energy $E_{\mathrm{B}}$ :

$E_{\mathrm{B}}=E_{\mathrm{D}}-E_{\mathrm{M}}$

$E_{\mathrm{M}}$ is the migration energy of lattice hydrogen diffusion, which was $5.63 \mathrm{~kJ} / \mathrm{mol}$ [37, 49-52]. The estimation according to the Kirchheim criterium gave binding energies between 18.3 and $30.7 \mathrm{~kJ} / \mathrm{mol}$. Hence, compared to micro-alloyed AHSS [42, 43] DP steels contain mainly shallow hydrogen trapping sites, e.g., trapping sites at dislocations [36, 38], lath martensite boundaries [42,43] or in volumes under micro-residual stress [53]. Although the titanium and niobium content in the chemical compositions of the investigated DP steels were not low, deep trapping sites, as they were found in literature for Titanium carbides and Niobium carbides [44, 46, 64], could not be observed in the measured TDS spectra. Linear heating to $900{ }^{\circ} \mathrm{C}$ did not reveal additional hydrogen peaks, which could be related hydrogen desorption from bulk. Basically, hydrogen desorption peaks at high temperatures in measured TDS spectra have to be treated carefully, because of the intensifying changes in the microstructure with rising temperatures. To the authors knowledge, microstructural evolution and phase transformation are currently not considered in an any TDS interpretation. Lin et al. [64] argued that TDS peaks at higher temperatures may superpose with hydrogen from dissociation of water molecules at the surface. In addition, Hitzigrath [65] studied the influence of the carrier gas on high temperature peaks and found an influence the high temperature peaks.

\section{Parametrization of the bulk diffusion models}

As shown in Fig. 5, the bulk diffusion models were fitted to the measured TDS spectra by means of a least-square optimization algorithm. The fittings were performed independently for each of the three DP steels and considered all three heating rates. The fitted sets of constant model parameters, as binding energy, migration energy and trap density, are summarized in Table 4 . While the binding energies were between 33.5 and $39.6 \mathrm{~kJ} / \mathrm{mol}$, the migration energies were between 8.4 and $12.8 \mathrm{~kJ} / \mathrm{mol}$. Migration energies for well-annealed pure iron are typically ranging from 6.0 to $12.9 \mathrm{~kJ} / \mathrm{mol}$ [37, 49-52]. Differences in the migration energy may arise compared to well-annealed pure iron from.

- higher dislocation density in ferrite phases of up to $10^{12} \mathrm{~m} / \mathrm{m}^{3}[56,66,67]$,

- the higher density of interfaces and

- tetragonal distortion of the martensite islands.

The fitted binding energies are slightly higher than the estimations according to the Kirchheim criterium $[30,31,63]$, as given in Table 3 , but they are in
Table 3 Measured desorption energies according to Kissinger's theory and corresponding $R^{2}$-values of the linear fits in the Choo-Lee plot

\begin{tabular}{llll}
\hline Steel & Desorption energy $\boldsymbol{E}_{\mathbf{D}}[\mathrm{kJ} / \mathrm{mol}]$ & $R^{2}$-value [-] & Binding energy $\boldsymbol{E}_{\mathbf{B}}[\mathrm{kJ} / \mathrm{mol}]$ \\
\hline DP600 & 24.3 & 0.970 & 18.7 \\
DP800 & 23.9 & 0.988 & 18.3 \\
DP1000 & 26.9 & 1.000 & 21.3 \\
DP1200 [62] & 29.8 & 0.968 & 24.2 \\
DP1200 [20] & 40.6 & - & 35.0 \\
\hline
\end{tabular}


(a)

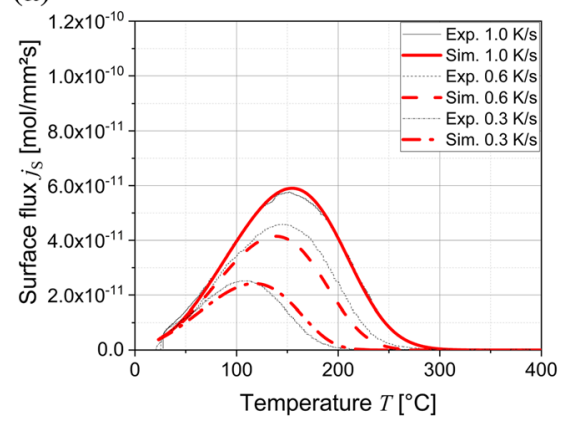

(b)

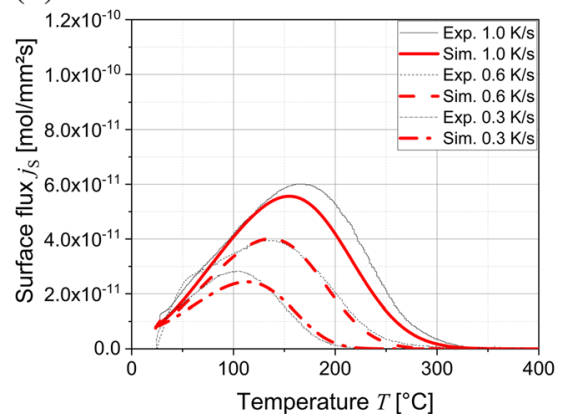

(c)

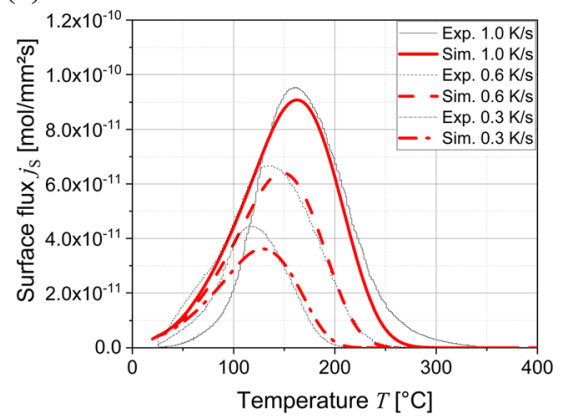

Figure 5 Comparison of simulated with measured TDS spectra as function of heating rate: a DP600, b DP800 and c DP1000.

Table 4 Inverse calibrated binding energies, migration energies and trap densities

\begin{tabular}{lllc}
\hline Parameter & DP600 & DP800 & DP1000 \\
\hline Binding energy $\mathrm{E}_{\mathrm{B}}[\mathrm{kJ} / \mathrm{mol}]$ & 36.8 & 33.5 & 39.6 \\
Migration energy $\mathrm{E}_{\mathrm{M}}[\mathrm{kJ} / \mathrm{mol}]$ & 10.8 & 12.9 & 6.0 \\
Trap density & & & \\
$\mathrm{N}_{\mathrm{T}}\left[\mathrm{mol} / \mathrm{mm}^{3}\right]$ & $1.7 \cdot 10^{-8}$ & $1.7 \cdot 10^{-8}$ & $3.8 \cdot 10^{-8}$ \\
\hline
\end{tabular}

reasonable agreement with the binding energies given in the literature for DP steels [20].

\section{Validation of model parametrizations}

To validate the parametrized bulk diffusion models, additional hydrogen desorption curves were recorded at room temperature. For that purpose, the samples were cleaned after electrochemical charging and dried with compressed air before the charged samples were stored under atmospheric conditions at room temperature to enable hydrogen desorption.
The remaining hydrogen contents in the samples were gradually measured by means of TDS. The heating rate was $1.0 \mathrm{~K} / \mathrm{s}$. As shown in Fig. 6a-c, the measured hydrogen content decreased parabolically with increasing desorption time in each of the three investigated DP steels. The calculated desorption curves agree $( \pm 0.3 \mathrm{wppm})$ with the results of the measurements for each of the investigated DP steels.

In addition, the parametrized diffusion models were applied to simulate TDS spectra for heating between 0.05 and $5.0 \mathrm{~K} / \mathrm{s}$ [31]. Extrapolating the almost linear curves beyond the measured heating rates allowed for comparing with measurement data of Schaffner et al. [62], as shown in Fig. 7. Note that Schaffner et al. used also the Bruker G8 Galileo analyser, but equipped with a mass spectrometer instead of a TCD. Even though Schaffner et al. recorded TDS spectra with lower heating rates and lower hydrogen contents, the agreement between the investigated DP steels seems to be reasonable.
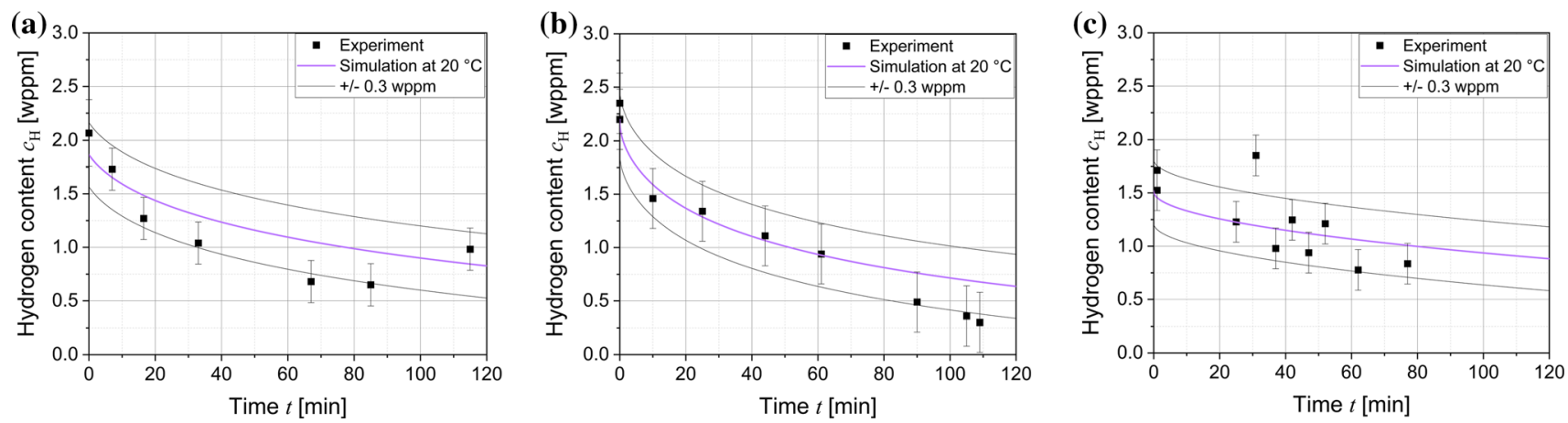

Figure 6 Validation of the model parametrizations by measuring the remaining hydrogen content after room temperature exposure of a DP600, b DP800 and c DP1000. 


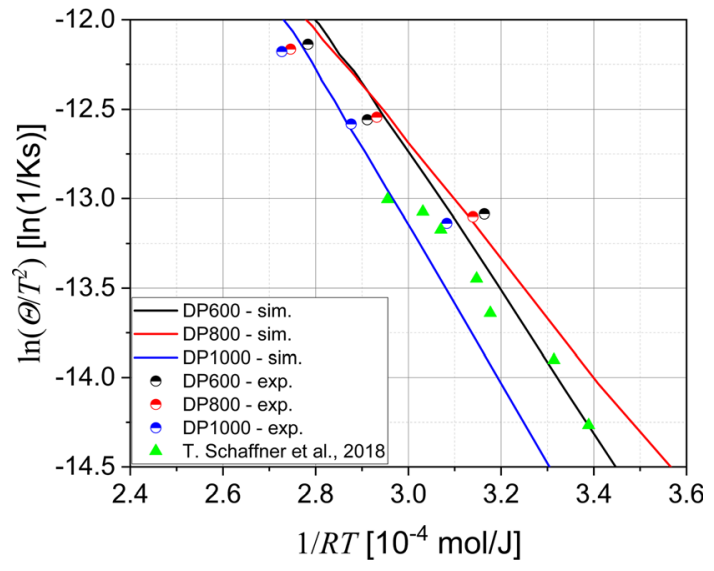

Figure 7 Choo-Lee plot of the measured and simulated TDS spectra.

\section{Role of current density on the effective diffusion coefficient}

Hydrogen permeation through DP samples was simulated using the parametrized bulk diffusion models. For that purpose, the constant sub-surface lattice hydrogen concentration $c_{\mathrm{L}, \mathrm{S}}$ was applied on the cathodic side. $c_{\mathrm{L}, \mathrm{S}}$ was zero on the anodic side. This gradient causes lattice hydrogen to steadily diffuse through the bulk until a stationary surface flux at the anodic side is reached. Under stationary conditions, the simulated lattice hydrogen concentration profile is linear in the sample, as shown in Fig. 8a. That relates the sub-surface lattice hydrogen concentration $\mathrm{c}_{\mathrm{L}, \mathrm{S}}$ at the cathodic side to the stationary surface flux $j_{\mathrm{S}}^{\infty}$ as

$c_{\mathrm{L}, \mathrm{S}}=\frac{j_{\mathrm{S}}^{\infty} \mathrm{s}}{D_{\mathrm{L}}}$

where $s$ is the sample thickness. As shown in Fig. 8a, the corresponding profile of the trapped hydrogen concentration is almost constant throughout the sample. Due to the limited density of trapping sites $N_{\mathrm{T}}$ compared to the density of lattice sits $N_{\mathrm{L}}$, trapping sites are saturated. Only close to the anodic side, the trapped hydrogen concentration drops to zero according to Eq. (6), because of the linear decreasing lattice hydrogen concentration to zero at the anodic side. This is in accordance with McNabb and Foster $[47,68]$, who stated that only lattice hydrogen diffuse and that the trapped hydrogen retards the long-range chemical diffusion. Consequently, the total hydrogen concentration according to Eq. (3) does not decrease linearly and is almost constant throughout the thickness auf the permeation sample.

The subsurface lattice hydrogen concentration at the cathodic side was increased from $10^{-20}$ to $10^{-1} \mathrm{~mol} / \mathrm{mm}^{3}$ for studying the effect of increasing sub-surface hydrogen coverage [69] on the simulated permeation transient. As shown in Fig. $8 \mathrm{~b}$, the higher sub-surface hydrogen coverage increases the stationary surface flux and decreases the hydrogen permeation time. The latter is related to the concentration dependence of the chemical diffusion coefficient [34], which is shown for the three investigated DP steels in Fig. 8c. Due to hydrogen trapping in the DP steels, the actual chemical diffusion coefficients vary over three orders of magnitude. At lattice hydrogen concentrations below $10^{-12} \mathrm{~mol} / \mathrm{mm}^{3}$, almost all hydrogen, which is absorbed by the material, is immediately trapped and cannot contribute to the long-range bulk diffusion. In other words, the chemical diffusion coefficient is limited by hydrogen trapping at low lattice concentrations. Between the lattice hydrogen concentrations of $10^{-12} \mathrm{~mol} / \mathrm{mm}^{3}$ and $10^{-8} \mathrm{~mol} / \mathrm{mm}^{3}$, the chemical diffusion coefficients rise rapidly from around $10^{-5} \mathrm{~mm}^{2} / \mathrm{s}$ to their maxima of around $10^{-3} \mathrm{~mm}^{2} / \mathrm{s}$. In the case of very high lattice hydrogen concentrations above $10^{-8} \mathrm{~mol} / \mathrm{mm}^{3}$, all trapping sites are fully occupied and the hydrogen bulk diffusion is only limited by lattice hydrogen diffusion through interstitial positions [36]. Thus, the maximum of the chemical diffusion coefficient is equal to the lattice diffusion coefficient $D_{\mathrm{L}}$, as defined by Eq. (5).

Consequently, long-range chemical hydrogen diffusion in DP steels depends on.

- The lattice hydrogen concentration and

- The investigated material, which is represented by the binding energy, the trap density and the migration energy.

It cannot be described by a single constant effective diffusion coefficient $D_{\text {eff }}$ [70] as proposed by the standard DIN EN ISO 17081 for hydrogen permeation measurements as [38, 41]

$D_{\text {eff }}=\frac{s^{2}}{6 \cdot t_{\text {lag }}}$

where $t_{\text {lag }}$ is the time needed for reaching $63 \%$ of the stationary current $i^{\infty}$. In addition to the concentration-dependent chemical diffusion coefficients, the parametrized bulk diffusion models were applied for 

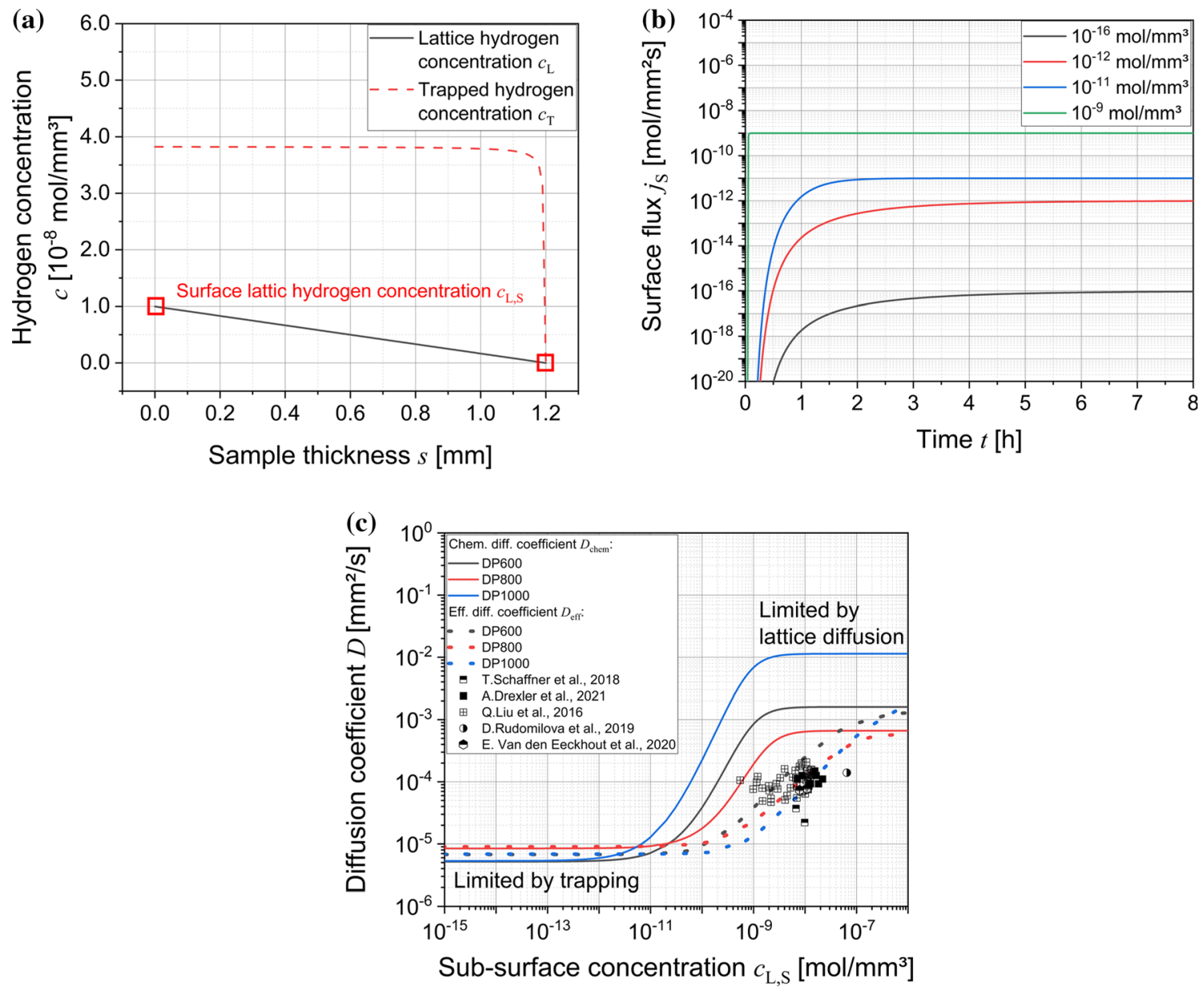

Figure 8 a Lattice and trapped hydrogen concentration profile through a DP1000 sample at stationary conditions. b Simulated permeation transient of DP1000 as function of surface

simulating the effective diffusion coefficients as function of the sub-surface lattice hydrogen concentration. Due to the decrease in the permeation time with increasing sub-surface lattice hydrogen concentration, the effective diffusion coefficients increase according to Eq. (10). That agrees with the experimental results from Rudomilova et al. [61], Liu et al. [71] or Zafra et al. [72, 73], who observed the measured diffusion rates to increase with increasing current density in an electrochemical permeation experiment. As shown in Fig. 8c, the concentration dependence of the chemical diffusion coefficients correlates with the simulated dependency of the effective diffusion coefficients on the sub-surface lattice hydrogen concentration.

For validating the simulation results, measured effective diffusion coefficients of DP steels from literature $[20,61,62,74]$ were added to Fig. 8c. Note concentration. c Simulated effective diffusion coefficient depending on the sub-surface lattice concentration.

that only literature data including information of the stationary current and sample thickness were added. This allowed for calculating the sub-surface lattice hydrogen concentration by using Eq. (9). The measured effective diffusion coefficients from literature increase with increasing sub-surface lattice hydrogen concentrations, which is in reasonable agreement with the predictions of the bulk diffusion models from the present work. However, even with current densities of $10 \mathrm{~A} / \mathrm{dm}^{2}\left(100 \mathrm{~mA} / \mathrm{cm}^{2}\right)$ [61] and thus with high cathodic sub-surface hydrogen concentrations [69], it was experimentally impossible to reach the lattice hydrogen diffusion coefficients of the investigated DP steels. The lattice diffusion coefficients of hydrogen in DP steels $\left(10^{-3} \mathrm{~mm}^{2} / \mathrm{s}\right)$, which were found in the present work by fitting TDS spectra, are slightly lower than those for pure and well-annealed iron [38, 41]. This observation agrees 
well with experimental results of Zafra et al. [72, 73], who recorded successive permeation transients $[74,75]$ and a saturation of the apparent diffusion coefficient of CrMo steels.

According to the simulation results and the comparison with literature, effective diffusion coefficients measured by means of a Devanathan-Stachurski [76] cell are only feasible if sufficient information about both the experimental setup and the raw data is included. A normalization of measured permeation curves without providing information about the stationary current density $i^{\infty}$ and the sample thickness makes the comparability with data from literature impossible. In addition, measuring the effective diffusion coefficient as a function of the applied cathodic current density enables estimating the curve of the concentration-dependent chemical diffusion coefficient of DP steels.

\section{Role of coatings as effective diffusion barriers for DP steels}

Hydrogen desorption during slow strain rate testing (SSRT) or constant load testing (CLT) [13, 77] of charged samples is a serious problem. Considering the decrease of the hydrogen content in the sample with testing time is crucial for the reliable evaluation of the hydrogen embrittlement susceptibility. For preventing hydrogen losses during the experiment, samples are often coated with zinc, cadmium or nickel, which possess much lower effective diffusion coefficients of hydrogen than DP steels and which are therefore used as active hydrogen diffusion barriers [78]. However, the coating process itself can introduce hydrogen into the steels as well as into the coatings. Due to the concentration dependence of the chemical diffusion coefficient, the additional hydrogen could increase the effective diffusion coefficients by magnitudes, as it was demonstrated for DP steels in the previous section. That would make the barriers permeable for hydrogen.

To study the possibility of reducing hydrogen desorption during testing by coating the samples after charging, a bulk diffusion model of a coated DP1000 steel sheet was established. Figure 9a shows a sketch of the cross section thought the model. The steel sheet is $1.2 \mathrm{~mm}$ and the coating on both surfaces is $10 \mu \mathrm{m}$ thick. Hydrogen diffusion in the coating layer was simplified by applying classical Fick's law of diffusion with constant effective diffusion

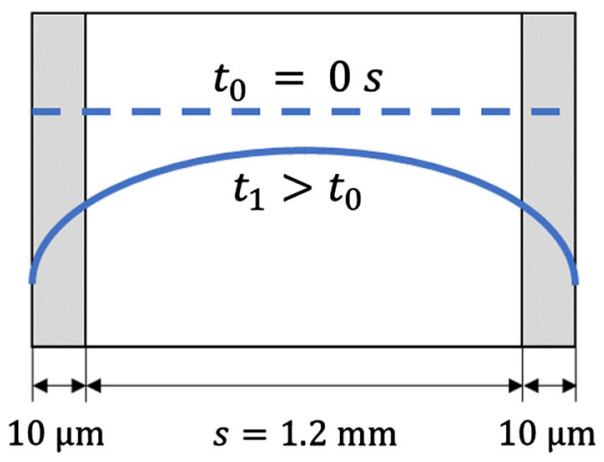

Figure 9 a Schematic of the profile of lattice hydrogen concentration in the coated sample used in the simulation.

coefficient and does not consider either oxide layers at the interface between coating and bulk nor intermediate layers. The lattice hydrogen concentration was assumed as homogenous in the initial state. Hydrogen desorption is simulated by setting the subsurface lattice hydrogen concentration to zero. Figure 10 shows the simulated decrease in the total hydrogen content in the DP1000 sample as a function of the desorption time and the effective hydrogen diffusion coefficient in the coating.

According to the simulations, the highest hydrogen desorption rate occurred for uncoated DP samples and a permanent hydrogen loss has to be considered during hydrogen embrittlement testing. However, adding coatings with an effective diffusion coefficient of $10^{-10} \mathrm{~mm}^{2} / \mathrm{s}$ can decrease the hydrogen desorption rate dramatically, which enables up to $10 \mathrm{~h}$ of testing without any hydrogen loss in the sample. A

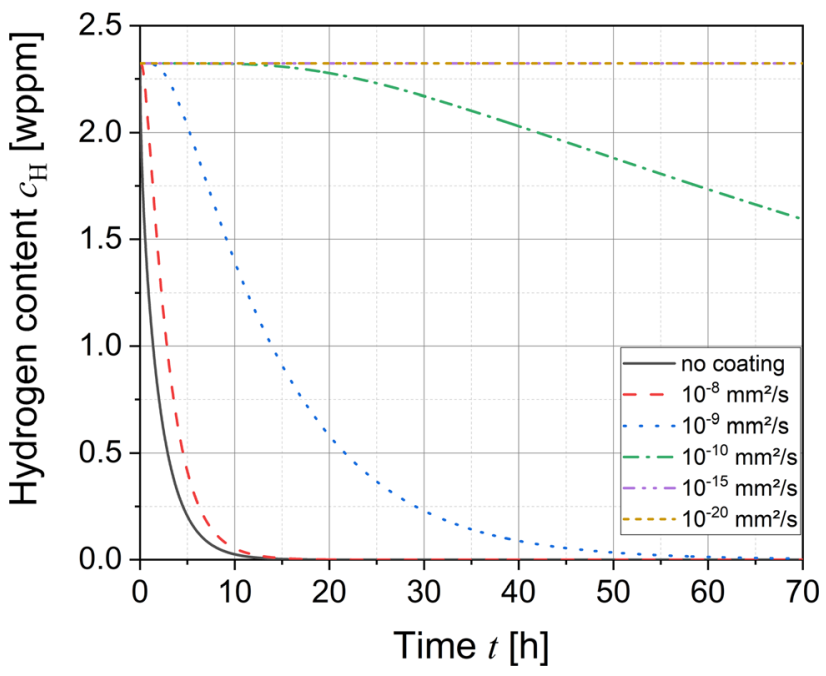

Figure 10 Influence of coatings on the hydrogen desorption of a DP1000 sample at room temperature. 
further decrease in the effective diffusion coefficient to $10^{-15} \mathrm{~mm}^{2} / \mathrm{s}$ would extend the testing time to more than three days.

Cao et al. [79] measured hydrogen diffusion through pure zinc-coated steels by means of electrochemical techniques. The effective diffusion coefficient of pure zinc layers was estimated to be in the order of $10^{-9} \mathrm{~mm}^{2} / \mathrm{s}\left(10^{-11} \mathrm{~cm}^{2} / \mathrm{s}\right)$. Surprisingly, this value is in a very sensitive range according to the simulations. The decrease to $10^{-10} \mathrm{~mm}^{2} / \mathrm{s}$ or the increase by one order of magnitude to $10^{-9} \mathrm{~mm}^{2} / \mathrm{s}$ can either cause rapid hydrogen desorption or a still homogenously charged sample after $10 \mathrm{~h}$ of testing, respectively.

If coated samples are used for preventing hydrogen desorption of charged samples during embrittlement testing and for extending the testing time, the hydrogen ingress into the coating layer, the role of oxides or other intermediate layers should be further investigated experimentally and numerically. For example, this could be done by electrochemical permeation with a step-wise increase in the current density. As shown for DP steels, a higher hydrogen concentration results in an increase in the chemical diffusion coefficient by orders of magnitude. Further investigations are necessary for fully understanding the role of coatings.

\section{Conclusion}

The present work models hydrogen bulk diffusion in three industrial produced dual phase (DP) steels. The parametrization of the models was based on fitting of thermal desorption spectroscopy measurements (TDS). The bulk diffusion models were validated by performing additional desorption experiments under atmospheric conditions. The overall accuracy of the models is \pm 0.3 wppm with respect to the measured hydrogen contents. Thus, the bulk diffusion model, which considers the McNabb and Foster postulate of lattice hydrogen diffusion and Oriani's trapping theory, is perfectly suited for describing hydrogen diffusion, trapping and desorption in DP steels. Furthermore, the parametrized and validated diffusion models are able to predict the linear curves in the Choo-Lee plots and to predict effective diffusion coefficients as a function of the stationary current. The calculated diffusion coefficients agree well with measured effective diffusion coefficients found in the literature. A measurement procedure is proposed for estimating qualitatively the concentration dependency of the chemical diffusion coefficient of DP steels by means of a Devanathan-Stachurski permeation cell and using the concept of the effective diffusion coefficient. It is found that only the triple of effective diffusion coefficient, sample thickness and stationary current density allows to compare permeation experiments from literature.

In addition, the role of metal coatings as possible hydrogen diffusion barriers for DP steels was numerically studied and compared with experimental data from the literature for pure zinc. Based on the simulation results, the effective diffusion coefficient of around $10^{-9} \mathrm{~mm} 2 / \mathrm{s}$ does not fully prevent hydrogen desorption of the underlying steel sheets. Further, experimental investigations are necessary to fully understand the role of coatings and to improve the bulk diffusion model.

\section{Funding}

Open access funding provided by Graz University of Technology.

\section{Declarations}

Conflict of interest The authors declare no conflict of interest.

Open Access This article is licensed under a Creative Commons Attribution 4.0 International License, which permits use, sharing, adaptation, distribution and reproduction in any medium or format, as long as you give appropriate credit to the original author(s) and the source, provide a link to the Creative Commons licence, and indicate if changes were made. The images or other third party material in this article are included in the article's Creative Commons licence, unless indicated otherwise in a credit line to the material. If material is not included in the article's Creative Commons licence and your intended use is not permitted by statutory regulation or exceeds the permitted use, you will need to obtain permission directly from the copyright holder. To view a copy of this licence, visit http://creativecommons.org/licen ses/by $/ 4.0 /$. 


\section{References}

[1] Raabe D, Sun B, Kwiatkowski Da Silva A et al (2020) Current challenges and opportunities in microstructure-related properties of advanced high-strength steels. Metall Mater Trans A Phys Metall Mater Sci 51:5517-5586. http s://doi.org/10.1007/s11661-020-05947-2

[2] Tasan CC, Diehl M, Yan D et al (2015) An overview of dualphase steels: advances in microstructure-oriented processing and micromechanically guided design. Annu Rev Mater Res 45:391-431. https://doi.org/10.1146/annurev-matsci-070214 $-021103$

[3] Ghassemi-Armaki H, Maaß R, Bhat SP et al (2014) Deformation response of ferrite and martensite in a dual-phase steel. Acta Mater 62:197-211. https://doi.org/10.1016/j.acta mat.2013.10.001

[4] Morsdorf L, Tasan CC, Ponge D, Raabe D (2015) 3D structural and atomic-scale analysis of lath martensite: effect of the transformation sequence. Acta Mater 95:366-377. h ttps://doi.org/10.1016/j.actamat.2015.05.023

[5] Du C, Hoefnagels JPM, Vaes R, Geers MGD (2016) Block and sub-block boundary strengthening in lath martensite. Scr Mater 116:117-121. https://doi.org/10.1016/j.scriptamat.201 6.01 .043

[6] Hutchinson B, Lindell D, Barnett M (2015) Yielding behaviour of martensite in steel. ISIJ Int 55:1114-1122. https://d oi.org/10.2355/isijinternational.55.1114

[7] Badinier G, Sinclair CW, Sauvage X et al (2015) Microstructural heterogeneity and its relationship to the strength of martensite. Mater Sci Eng A 638:329-339. h ttps://doi.org/10.1016/j.msea.2015.04.088

[8] Scott CP, Shalchi Amirkhiz B, Pushkareva I et al (2018) New insights into martensite strength and the damage behaviour of dual phase steels. Acta Mater 159:112-122. h ttps://doi.org/10.1016/j.actamat.2018.08.010

[9] Depover T, Pérez Escobar D, Wallaert E et al (2014) Effect of hydrogen charging on the mechanical properties of advanced high strength steels. Int $\mathrm{J}$ Hydrog Energy 39:4647-4656. https://doi.org/10.1016/j.ijhydene.2013.12. 190

[10] Koyama M, Tasan CC, Akiyama E et al (2014) Hydrogenassisted decohesion and localized plasticity in dual-phase steel. Acta Mater 70:174-187. https://doi.org/10.1016/j.acta mat.2014.01.048

[11] Barrera O, Bombac D, Chen Y et al (2018) Understanding and mitigating hydrogen embrittlement of steels: a review of experimental, modelling and design progress from atomistic to continuum. J Mater Sci 53:6251-6290. https://doi.org/10. 1007/s10853-017-1978-5
[12] Bergmann C (2020) Hydrogen embrittlement resistance of advanced high strength steel grades in automotive applications. Ruhr-Universität Bochum

[13] Bergmann C, Mraczek K, Kroger B, et al (2018) Hydrogen embrittlement resistance evaluation of advanced high strength steels in automotive applications. In: SteelyHydrogen, Ghent p. A01

[14] Wu R, Ahlström J, Magnusson H, et al (2015) R-13-45 Charging, degassing and distribution of hydrogen in cast iron

[15] Polyanskiy VA, Belyaev AK, Alekseeva EL et al (2019) Phenomenon of skin effect in metals due to hydrogen absorption. Contin Mech Thermodyn 31:1961-1975. http s://doi.org/10.1007/s00161-019-00839-2

[16] Massone A, Manhard A, Drexler A et al (2020) Addressing $\mathrm{H}$-material interaction in fast diffusion materials - a feasibility study on a complex phase steel. Materials (Basel) 13:4677. https://doi.org/10.3390/ma13204677

[17] Massone A, Manhard A, Jacob W et al (2020) An SEM compatible plasma cell for in situ studies of hydrogen-material interaction. Rev Sci Instrum 91:043705. https://doi.org/ 10.1063/1.5142043

[18] Taketomi S, Matsumoto R (2019) Atomistic simulations of hydrogen effects on lattice defects in alpha iron. In: Hsueh $\mathrm{CH}$. et al. (eds) Handbook of mechanics of materials. Springer, Singapore. https://doi.org/10.1007/978-981-10-68 84-3_11

[19] Drexler A, Domitner J, Sommitsch C (2021) Modeling of hydrogen diffusion in slow strain rate (SSR) testing of notched samples. In: Polyanskiy VA, Belyaev AK (eds) Advances in hydrogen embrittlement study, 143rd edn. Springer, Cham, pp 87-111

[20] Drexler A, Bergmann C, Manke G et al (2021) On the local evaluation of the hydrogen susceptibility of cold-formed and heat treated advanced high strength steel (AHSS) sheets. Mater Sci Eng A 800:140276. https://doi.org/10.1016/j.mse a.2020.140276

[21] Drexler A, Ecker W, Winzer N et al (2018) A step towards numerical evaluation of the local hydrogen susceptibility of punched and cold-formed advanced high strength steel (AHSS) sheets. In: Duprez L (ed) SteelyHydrogen. Ocas, Guelph. http://steelyhydrogen2018proc.be/articles/pdf/2

[22] Ozdirik B, Suter T, Hans U et al (2019) Study of the hydrogen uptake in deformed steel using the microcapillary cell technique. Corros Sci 155:55-66. https://doi.org/10.10 16/j.corsci.2019.04.029

[23] Zafra A, Belzunce J, Rodríguez C, Fernández-Pariente I (2020) Hydrogen embrittlement of the coarse grain heat affected zone of a quenched and tempered $42 \mathrm{CrMo} 4$ steel. 
Int J Hydrog Energy 45:16890-16908. https://doi.org/10.10 16/j.ijhydene.2020.04.097

[24] Zafra A, Peral LB, Belzunce J, Rodríguez C (2019) Effects of hydrogen on the fracture toughness of $42 \mathrm{CrMo} 4$ steel quenched and tempered at different temperatures. Int J Press Vessel Pip 171:34-50. https://doi.org/10.1016/j.ijpvp.2019. 01.020

[25] Drexler A, Bergmann C, Manke G et al (2021) Local hydrogen accumulation after cold forming and heat treatment in punched advanced high strength steel sheets. J Alloys Compd 856:158226. https://doi.org/10.1016/j.jallc om. 2020.158226

[26] Depover T, Wallaert E, Verbeken K (2016) Fractographic analysis of the role of hydrogen diffusion on the hydrogen embrittlement susceptibility of DP steel. Mater Sci Eng A 649:201-208. https://doi.org/10.1016/j.msea.2015.09.124

[27] Rhode M, Mente T, Steppan E et al (2018) Hydrogen trapping in T24 Cr-Mo-V steel weld joints-microstructure effect vs. experimental influence on activation energy for diffusion. Weld World 62:277-287. https://doi.org/10.1007/ s40194-017-0546-6

[28] Kissinger HE (1957) Reaction kinetics in differential thermal analysis. Anal Chem 29:1702-1706. https://doi.org/10.1021 /ac60131a045

[29] Lee JY, Choo WY (1982) Thermal analysis of trapped hydrogen in pure iron. Metall Trans A 13A:135-140

[30] Kirchheim R (2016) Bulk diffusion-controlled thermal desorption spectroscopy with examples for hydrogen in iron. Metall Mater Trans A Phys Metall Mater Sci 47:672-696. h ttps://doi.org/10.1007/s11661-015-3236-2

[31] Drexler A, Vandewalle L, Depover T et al (2021) Critical verification of the Kissinger theory to evaluate thermal desorption spectra. Int J Hydrogen Energy 46:39590-39606. https://doi.org/10.1016/j.ijhydene.2021.09.171

[32] Toribio J, Kharin V (2015) A generalised model of hydrogen diffusion in metals with multiple trap types. Philos Mag 95:3429-3451. https://doi.org/10.1080/14786435.2015. 1079660

[33] Drexler A, He S, Razumovskiy V et al (2020) Verification of the generalised chemical potential for stress-driven hydrogen diffusion in nickel. Philos Mag Lett 100:513-523. https://d oi.org/10.1080/09500839.2020.1808253

[34] Svoboda J, Mori G, Prethaler A, Fischer FD (2014) Determination of trapping parameters and the chemical diffusion coefficient from hydrogen permeation experiments. Corros Sci 82:93-100. https://doi.org/10.1016/j.corsci.2014.01.002

[35] Nagumo M (2016) Fundamentals of hydrogen embrittlement. Springer, Singapore
[36] Kholtobina AS, Pippan R, Romaner L et al (2020) Hydrogen trapping in bcc Iron. Materials (Basel) 13:2288. https://doi. org/10.3390/ma13102288

[37] Kiuchi K, McLellan RB (1983) The solubility and diffusivity of hydrogen in well-annealed and deformed iron. Acta Metall 31:961-984. https://doi.org/10.1016/0001-6160(83)9 0192-X

[38] Drexler A, Siegl W, Ecker W et al (2020) Cycled hydrogen permeation through Armco iron-a joint experimental and modeling approach. Corros Sci 176:109017. https://doi.org/ 10.1016/j.corsci.2020.109017

[39] Mine Y, Tsumagari T, Horita Z (2010) Hydrogen trapping on lattice defects produced by high-pressure torsion in Fe-0.01 mass\% C alloy. Scr Mater 63:552-555. https://doi.org/10. 1016/j.scriptamat.2010.05.027

[40] Somerday BP, Dadfarnia M, Balch DK et al (2009) Hydrogen-assisted crack propagation in austenitic stainless steel fusion welds. Metall Mater Trans A 40:2350-2362. https://d oi.org/10.1007/s11661-009-9922-1

[41] Siegl W, Ecker W, Klarner J, et al (2019) Hydrogen trapping in heat treated and deformed Armco iron. In: NACE-international corrosion conference series. pp 1-12

[42] Drexler A, Depover T, Verbeken K, Ecker W (2019) Modelbased interpretation of thermal desorption spectra of Fe-C-Ti alloys. J Alloys Compd 789:647-657. https://doi.org/10.10 16/j.jallcom.2019.03.102

[43] Drexler A, Depover T, Leitner S et al (2020) Microstructural based hydrogen diffusion and trapping models applied to Fe-C X alloys. J Alloys Compd 826:154057. https://doi.org/ 10.1016/j.jallcom.2020.154057

[44] Di Stefano D, Nazarov R, Hickel T et al (2016) First-principles investigation of hydrogen interaction with TiC precipitates in $\alpha-\mathrm{Fe}$. Phys Rev B 93:184108. https://doi.org/10. 1103/PhysRevB.93.184108

[45] Depover T, Verbeken K (2016) Evaluation of the effect of V4C3 precipitates on the hydrogen induced mechanical degradation in $\mathrm{Fe}-\mathrm{C}-\mathrm{V}$ alloys. Mater Sci Eng A 675:299-313. https://doi.org/10.1016/j.msea.2016.08.053

[46] Depover T, Verbeken K (2016) The effect of $\mathrm{TiC}$ on the hydrogen induced ductility loss and trapping behavior of $\mathrm{Fe}-$ C-Ti alloys. Corros Sci 112:308-326. https://doi.org/10.10 16/j.corsci.2016.07.013

[47] McNabb A, Foster PK (1963) A new analysis of the diffusion of hydrogen in iron and ferritic steels. Trans Met Soc AIME 227:618-627

[48] Svoboda J, Fischer FD (2012) Modelling for hydrogen diffusion in metals with traps revisited. Acta Mater 60:1211-1220. https://doi.org/10.1016/j.actamat.2011.11. 025 
[49] Grabke HJ, Riecke E (2000) Absorption and diffusion of hydrogen in steels. Mater Tehnol 34:331-432

[50] Hagi H (1994) Diffusion coefficient of hydrogen in iron without trapping by dislocations and impurities. Mater Trans JIM 35:112-117. https://doi.org/10.2320/matertrans1989.35. 112

[51] Hagi H, Hayashi Y, Ohtani N (1979) Diffusion coefficient of hydrogen in pure iron between 230 and $300 \mathrm{~K}$. Trans Japan Inst Met 20:349-357

[52] Nelson HG, Stein JE (1973) Gas-phase hydrogen permeation through alpha iron, 4130 steel, and 304 stainless steel from less than $100{ }^{\circ} \mathrm{C}$ to near $600{ }^{\circ} \mathrm{C}$. Washington, D.C

[53] Hussein A, Krom AHM, Dey P et al (2021) The effect of hydrogen content and yield strength on the distribution of hydrogen in steel: a diffusion coupled micromechanical FEM study. Acta Mater 209:116799. https://doi.org/10.1016/ j.actamat.2021.116799

[54] Echeverri Restrepo S, Di Stefano D, Mrovec M, Paxton AT (2019) Density functional theory calculations of ironvanadium carbide interfaces and the effect of hydrogen. Int $\mathrm{J}$ Hydrog Energy 5:2-9. https://doi.org/10.1016/j.ijhydene.20 19.11 .102

[55] Drexler A, He S, Pippan R et al (2021) Hydrogen segregation near a crack tip in nickel. Scr Mater 194:113697. h ttps://doi.org/10.1016/j.scriptamat.2020.113697

[56] Ramazani A, Mukherjee K, Schwedt A et al (2013) Quantification of the effect of transformation-induced geometrically necessary dislocations on the flow-curve modelling of dual-phase steels. Int J Plast 43:128-152. https://doi.org/10. 1016/j.ijplas.2012.11.003

[57] Speich GR, Miller RL (1979) Mechanical properties of Ferrite-Martensite steels. In: Struct. Prop. Dual-Phase Steels. pp. $145-182$

[58] Wang YF (2020) Effect of initial hydrogen distribution on the parameter extraction of the thermal desorption spectra: a finite element study. Int J Hydrog Energy 45:23754-23764. https://doi.org/10.1016/j.ijhydene.2020.06.214

[59] Winzer N, Rott O, Thiessen R et al (2016) Hydrogen diffusion and trapping in Ti-modified advanced high strength steels. Mater Des 92:450-461. https://doi.org/10.1016/j.ma tdes.2015.12.060

[60] Begić Hadžipašić A, Malina J, Nižnik Š (2011) The influence of microstructure on hydrogen diffusion in dual phase steel. Acta Metall Slovaca 17:129-137

[61] Rudomilova D, Prošek T, Salvetr P et al (2020) The effect of microstructure on hydrogen permeability of high strength steels. Mater Corros 71:909-917. https://doi.org/10.1002/m aco. 201911357

[62] Schaffner T, Hartmaier A, Kokotin V, Pohl M (2018) Analysis of hydrogen diffusion and trapping in ultra-high strength steel grades. J Alloys Compd 746:557-566. https://d oi.org/10.1016/j.jallcom.2018.02.264

[63] Raina A, Deshpande VS, Fleck NA (2018) Analysis of thermal desorption of hydrogen in metallic alloys. Acta Mater 144:777-785. https://doi.org/10.1016/j.actamat.2017. 11.011

[64] Lin YC, McCarroll IE, Lin YT et al (2020) Hydrogen trapping and desorption of dual precipitates in tempered lowcarbon martensitic steel. Acta Mater 196:516-527. https://d oi.org/10.1016/j.actamat.2020.06.046

[65] Hitzigrath F (2017) Bestimmung von diffusiblem Wasserstoff in hochfesten Stählen in Bezug auf die Gitterstruktur. Universität Duisburg- Essen

[66] Tsipouridis P (2006) Mechanical properties of dual-phase steels. Technical University of Muenchen

[67] Kadkhodapour J, Schmauder S, Raabe D et al (2011) Experimental and numerical study on geometrically necessary dislocations and non-homogeneous mechanical properties of the ferrite phase in dual phase steels. Acta Mater 59:4387-4394. https://doi.org/10.1016/j.actamat.2011.03. 062

[68] Polyanskiy VA, Belyaev AK, Chevrychkina AA et al (2021) Impact of skin effect of hydrogen charging on the Choo-Lee plot for cylindrical samples. Int $J$ Hydrog Energy 46:6979-6991. https://doi.org/10.1016/j.ijhydene.2020.11. 192

[69] Pérez Escobar D, Miñambres C, Duprez L et al (2011) Internal and surface damage of multiphase steels and pure iron after electrochemical hydrogen charging. Corros Sci 53:3166-3176. https://doi.org/10.1016/j.corsci.2011.05.060

[70] Fischer FD, Mori G, Svoboda J (2013) Modelling the influence of trapping on hydrogen permeation in metals. Corros Sci 76:382-389. https://doi.org/10.1016/j.corsci.201 3.07 .010

[71] Liu Q, Atrens AD, Shi Z et al (2014) Determination of the hydrogen fugacity during electrolytic charging of steel. Corros Sci 87:239-258. https://doi.org/10.1016/j.corsci.201 4.06.033

[72] Zafra A, Peral LB, Belzunce J (2020) Hydrogen diffusion and trapping in A $42 \mathrm{CrMo} 4$ quenched and tempered steel: influence of tempering temperature. Int J Hydrog Energy 45:31225-31242. https://doi.org/10.1016/j.ijhydene.2020.08 .134

[73] Zafra A, Belzunce J, Rodríguez C (2020) Hydrogen diffusion and trapping in $42 \mathrm{CrMo} 4$ quenched and tempered steel: Influence of quenching temperature and plastic deformation. Mater Chem Phys 255:123599. https://doi.org/10.1016/j.ma tchemphys.2020.123599 
[74] Liu Q, Venezuela J, Zhang M et al (2016) Hydrogen trapping in some advanced high strength steels. Corros Sci 111:770-785. https://doi.org/10.1016/j.corsci.2016.05.046

[75] Liu Q, Atrens A (2015) Reversible hydrogen trapping in a 3.5NiCrMoV medium strength steel. Corros Sci 96:112-120. https://doi.org/10.1016/j.corsci.2015.04.011

[76] Devanathan MAV, Stachurski Z (1962) The adsorption and diffusion of electrolytic hydrogen in palladium. Proc R Soc London Ser A Math Phys Sci 270:90-102. https://doi.org/10. 1098/rspa.1962.0205

[77] Takai K, Shoda H, Suzuki H, Nagumo M (2008) Lattice defects dominating hydrogen-related failure of metals. Acta Mater 56:5158-5167. https://doi.org/10.1016/j.actamat.200 8.06 .031
[78] Bhadeshia HKDH (2016) Prevention of hydrogen embrittlement in steels. ISIJ Int 56:24-36. https://doi.org/10.2355/ isijinternational.ISIJINT-2015-430

[79] Cao JL, Li LT, Wu JX et al (2002) Diffusion of hydrogen in a steel substrate absorbed during zinc and zinc-silica electroplating. Corrosion 58:698-702. https://doi.org/10.5006/1. 3287700

Publisher's Note Springer Nature remains neutral with regard to jurisdictional claims in published maps and institutional affiliations. 